\title{
Smart Technology and Not So Smart Sleep Quality
}

\author{
Kathy Sexton-Radek ${ }^{1 *}$, Elizabeth Borek ${ }^{2}$, Dylin Coons ${ }^{3}$, Sandra Mohama ${ }^{4}$ \\ ${ }^{1}$ Elmhurst College, Elmhurst, Illinois, United States \\ ${ }^{2}$ Roosevelt University, Chicago, Illinois, United States \\ ${ }^{3}$ Eastern Illinois University, Charleston, Illinois, United States \\ ${ }^{4}$ Dominican University, River Forest, Illinois, United States \\ Email: ksrsleep@aol.com
}

\begin{abstract}
Sleep quality has been identified as "poor" overall, in young adults. Traditionally, sleep hygiene rules composed of a set of positive health habits conducive to relaxation and falling asleep are provided to address poor sleep. To the young adult population of 18-30 years, poor sleep quality is also related to variable sleep patterns (Sexton-Radek, 2008). Jacobsen \& Forste (2011) reported that the constant technology use (i.e., smartphone, tablet) by young adults interferes with their sleep. The modification of a sleep schedule is regularly exercised by young adults; -they give up sleep for social activities in person or online (Sexton-Radek, 2008). Current use of technology at pre-sleep is undocumented in the young adult population. This study was aimed at measuring sleep hygiene, along with technology use in young adults. Results from a questionnaire administered internationally to a young adult population indicated widespread, constant use of technology at pre-sleep in the young adult population.
\end{abstract}

Keywords: Sleep quality, sleep hygiene, young adults, emerging adults, sleep, sleep knowledge.

\section{Introduction}

Sleep Disturbance is common among young adults aged 18-30 years. The experiences of academic/work stress coupled with freedom of choice in their schedule often leads to variable sleep patterns. (SextonRadek, 2008). In recent polls conducted by the National Sleep Foundation (NSF), the sleep of young adults is worsening. A reported decline in the last twenty years for this group of 6.5 hours from 7.5 hours was identified from the National Sleep Foundation polls. Further, academic difficulties and mood changes are often identified as problematic in studies of College Students with poor sleep. Pilcher, Ginter and Sadowksy (1997) reported more students reporting anxiety and depression symptoms. Declines in grades also depicts the circumstance of poor sleep, heightened expressed emotions in college students. Jacobsen \& Forste (2011) commented on constant technology use (i.e., smartphone use, tablet) by young adults, seemingly to remain in social contact and aware of social happenings. However, reports of blunted social relations and poor sleep due to excessive focus on technology (Jacobsen \& Forste, 2011); Sexton-Radek, 2008). Investigations of academic/cognitive activity in College students with reported poor sleep indicated tasks such as taking notes from readings and mathematical problems as the most difficult to accomplish (Sexton-Radek, 2008). Similarly, young adults in the work force identified work stress in terms of ability to perform at work as stressful (Sexton-Radek, 2008).

These findings emphasize the associations between poor sleep and academic/work performance in young adults. The variable sleep pattern of some early bedtimes and wake times alternating with abbreviated sleep duration and then sleep of long durations - seemingly to catch up-is typical in the young adult (Sexton-Radek, 2008). The demands of their academics along with choices they make based on social cues and responsibilities perpetuate this pattern. The net result of the chronic, remitting sleep deprivation of the variable sleep pattern is largely in terms of reductions in total sleep time, loss of a REM period and reductions in stage 2 nREM sleep (Sexton-Radek, 2008).

Young adults are notorious for having irregular sleep habits (i.e., variable sleep), including a more evening chronotype, disturbed sleep, and poor quality and quantity. Sleep quantity and academic performance among undergraduate college students are significantly related, with less sleep generally associated with lower grade point average (GPA) (Sexton-Radek, 2008). Napping has been shown to 
improve alertness and performance; however, the prevalence of napping among college students and the relation to GPA and circadian rhythm type has been identified to be an evening type chronotype (Sexton-Radek, 2008). The American Psychological Association release of the "Stress in America" poll in 2015 presented findings of the general publics' identification of leading sources of stress on their lives by age cohort. The poll referred to 340 Millennials (classification of age closest to the young adult 18-30 years) responds to the survey; an overall stress level of 5.4 on a 10-point scale. This score places them higher than the Baby boomers, Matures, and Generation Xers classifications. 52\% of the Millennials responded that the stress caused them to lay awake at night in the past month (Stress in America, 2014). Concepcion et al. (2014) survey of Chilean College students indicated an Eveningness Chronotype, common complaints of poor sleep, feelings of anxiety and upset and worry related to academic performance. Sing and Wong (2010) conducted a survey of College students in Hong Kong. The results indicated approximately $70 \%$ of the participants had sleep onset insomnia secondary to academic worries. Studies of sleep problems in college students, it was determined, result in an overall decrease from 7.4 hours to 6.8 hours of sleep per night (Sing and Wong, 2010).

In formal cognitive behavior therapy (CBTi) interventions for disturbed sleep, sleep hygiene is considered the last factor to address beyond the intake interview data gathering. The analysis of other features of $\mathrm{CBTi}$ indicates that sleep hygiene contributes to sleep disturbance but that good sleep hygiene has not been shown to improve sleep disturbances. Stepanski and Wyatt (2003) recommended a focus on the sleep hygiene guidelines for use with individuals in treatment. Sleep hygiene is a component of treatments for sleep disturbance. A listing of common factors known to disturb sleep (e.g., nicotine use, caffeine use) are among the items on the commonly used list first published by Dr. Hauri of Mayo Clinic in the 1980s (Hauri, 1991). Voinescu and Szentagotai-Tatar (2015) reported none significant findings from their investigation that trained the experimental group of college students to be more aware of sleep hygiene principles. Posner and Gehrman (2011) emphasize the provision of a rationale for the sleep hygiene to everyone. For example, requesting the chronic cigarette smoking to refrain from smoking would provoke tension rather than support to relieve a patient's sleep disturbance. Pearch et. al (2016) advocated the targeting of sleep hygiene use and sleep quality improvement as it was found to be associated with overall well-being in college students. Gellis, Park, Stotsky and Taylor (2014) reported some $13 \%$ of their interviewed sample of college students met criteria for the Insomnia diagnosis. They attributed the poor sleep quality to the frequent engagement in inconsistent sleep-wake schedules and lounging and worry/thinking about academic stress. With a sleep hygiene instruction, variable sleep scheduling was reported to remain in this sample of college students (Gellis, Park, Stotsky, Taylor, 2014). Kloss, Nash, Walsh, Culnan, Horsey and Sexton-Radek (2016) identified the utility of a sleep education workshop for college students in reducing sleep loss and negative mood. This study was designed to measure young adult sleep quality and to obtain a measurement of technology use in relation to their sleep.

\section{Method}

Participants: The sampling for participants was set up with a Facebook page and the purchase of posting privedges of the page internationally for a ninety-day interval during the months of April-MayJune of 2018. A Qualtrics generated survey was posted on the Facebook page with an introduction to the study and invitation to open the link to the survey. The opening of the link led the potential participant to an informed consent statement and the selection of the enter key constituted informed consent and acknowledgement of meeting inclusion criteria. The inclusion criteria were being within the ages of 18-30 years old. There are no exclusion criteria.

Instruments: A twenty-two item survey was generated using Qualtrics software based on literature reviews of topics on sleep hygiene and young adult sleep quality. Several questions focused on technology use. The survey took four minutes to take. The reading level was gauged to be at the sixth grade in America schools. The survey was in English and sent only to countries with English as the primary language.

Results: The Qualtrics software provided a summarization of each question in terms of the frequency of each endorsed area. The Qualtrics software also provided a data download function where the data collected was saved to a SPSS file format. The SPSS file was uploaded into SPSS and both descriptive 
and interpretative analysis were conducted on the data sets. Each question was treated as a separate variable.

108 individuals from four continents, representing eight countries replied to the survey. The inclusion criteria requested the person to be between 18 and 30 years old. The participant response of $91 \%$ was measured for having two or more pre-bedtime tasks. $88 \%$ of the participants did not have a predetermined bedtime. $46 \%$ of the participants had a predetermined wakeup time during the weekdays. It was found that $94 \%$ of the participants stated that they have varying wakeup times during the weekend. $72 \%$ of the participants took naps with $80 \%$ of the naptimes being on the weekends or late afternoon/early evening time. $66 \%$ of the participants are pleased with their health with $37 \%$ of the participants working out 3 or greater times per week.

The participants endorsed using technology regularly. On average, the participants reported using their smartphones for over 6 hours per day, their computer/laptop/MacBook for 4-6 hours per day, video game playing and tablet use for 0-3 hours per day. $64 \%$ of the participants stated that they checked social media constantly. $43 \%$ of the participants stated that check their phone if awoken in the middle of the night. $91 \%$ of the participants stated that they are using technology right up to bedtime. The participants feel the most worn out at school or work during the day. $95 \%$ of the participants ranked work/school, family/friend relationships, then sleep, then physical activity/working out as important in their life.

\section{Discussion}

The focus of the study was supported. The self-reported results indicate a variable sleep pattern with no specified bedtime or wake time. This condition perpetuates the cycle of little sleep experienced until the need for sleep propels the young adult to oversleep in their attempt to recover, then this is followed by short sleep lengths so social pursuits are enacted. The oversleeping occurs on non-scheduled (no class, no work) of the weekend. These times also included excessive napping. It may be the case that collectively, as a group, young adults experience a version of the adolescent omnipresence/narcissism where sleep may be considered down time. Sleep health, including a regular sleep schedule, no napping to keep sleep consolidated and presleep behaviors conducive to sleep contribute to overall health (Carpenter, 2013; Sexton-Radek, 2008; Stepanski and Wyatt, 2003; Walch and Forger, 2017). The young adult participants in this study did not consider sleep to be as important.

Significant to the focus of this study, is the $91 \%$ value obtained of participants using technology up to sleep time. New work in the ergonomics of the sleep environment have has identified the intrusion to the brain of bright pixel stimulation from a computer/smartphone/video monitor screen (Branley, 2017; Carpenter, 2013; Peach, 2016; Posner \& Gehrman, 2011, Voinescu and Szentagontai-Tatar, 2015). This intrusion, it is believed, stimulates the brain to function as if on wake time. A second component of this technology use at presleep is the amount of emotional stimulation this brings to the young adult sleeper. It has been identified that excessive worry coupled with high sleep need in the young adult interferes with their ability to relax and fall asleep (Kloss, Nash, Walsh, Culnan, Horsey and Sexton-Radek, 2016).

Additional intervention to young adults is needed to provide them with information and strategies to control their sleep and lifestyle to maintain or for some, develop, good health. It is essential that basics of sleep health such as the cognitive, emotional and memory outcomes of good versus poor sleep be understood. This understanding would help ameliorate the prominent stress (i.e., academic, work) that young adults experience. The distribution of the sleep education should be online in a modality that is common for young adults. Importantly, sleep hygiene lessons, however conveyed, need to include limits on technology use (e.g., turning all technology off one hour before bedtime, using screen adaptors on laptops/smartphones/ tablets that limit the visual stimulation several hours before sleep).

\section{References}

1. Branley, D. (2017). Informate Mobile Intelligence First to Measure Smartphone Usage Internationally, Report Currently Tracks 12 Countries and Will Expand to 25 by the End of 2015. Informate. http://www. informatemi.com/newsletter10022015.html. 
2. Carpenter, S. (2013). Awakening to Sleep. American Psychological Association Monitor, 44(1). http://www.apa. org/monitor/2013/01/awakening.aspx

3. Concepcion, T. Barbosa, C., Belex, J.C., Pepper, M., Andrade, A., Gelaye, B., Yanez, D., \& Williams, M.A. (2014). Daytime Sleepiness, Poor Sleep Quality, Eveningness Chronotype, and Common Mental Disorders Among Chilean College Students. Journal of American College Health, 62(7), 441-448.

4. Gellis, L, Park, A., Stotsky, M., Taylor, D. (2014). Associations between sleep hygiene and insomnia Severity in college students: Cross-sectional and prospective analyses. Behavior Therapy, 45(6), 806-816.

5. Hauri, P. J. (1991). Chapter 5: Sleep Hygiene, Relaxation Therapy, and Cognitive Interventions, pp65-84. In: P.J. Hauri (ed.). Case Studies in Insomnia Critical Issues in Psychiatry. Massachusetts: Springer Publications. https://doi.org/10.107/978-1-4757-9586-8-5.

6. Jacobsen, W.C. \& Forste, R. (2011). The Wired Generation: Academic and Social Outcomes of Electronic media use Among University Students. Cyperpsychology, Behavior and Social Networking, 14(5), 275-280.

7. Kloss, J.D., Nash, C.O., Walsh, C.M., Culnan, E., Horsey, S. and Sexton-Radek, K. (2016). A "Sleep 101" Program for College Students Improves Sleep Hygiene Knowledge and Reduces Maladaptive Beliefs about Sleep. Behavioral Medicine, 42: 48-56. Doi:10.108/08964289.2014

8. Peach, H. (2016). Sleep hygiene and sleep quality as predictors of positive and negative dimensions of Mental health in college students. Cogent Psychology, 3(1). ISSN 2331-1908.

9. Pilcher, J.J., Ginter, D.R., \& Sadowsky, B. (1997). Sleep Quality versus Sleep Quantity Relationships Between Sleep and Measures of Health Well-Being and Sleepiness in College Students. Journal of Psychosomatic Research, 42(6): 583-596. S0022-3999(97)00004-4.

10. Posner, D. \& Gehrman, P. (2011). Chapter 3 Sleep Hygiene. In: M. Perlis, M. Aloia, \& B. Kuhn (Ed.) Behavioral Treatments for Sleep Disorders. pp 31-43. Doi: 10.1016/B978-0-12-381522-4.00012-2.

11. Sexton-Radek, K. (2008). Sleep Quality in Young Adults. New York: Mellon Press.

12. Sing, C.Y. \& Wong, W.S. (2010). Prevalence of Insomnia and its Psychosocial Correlates Among College Students in Hong Kong. Journal of American College Health, 59(3): 174-182.

13. Stepanski, E.J. \& Wyatt, J., K. (2003). Use of sleep hygiene in the treatment of insomnia. Sleep Medicine Reviews, 7(3): 215-225.

14. Stress in America Paying with Our Health (2015). Stress in America poll. Washington, D.C.: American Psychological Association.

15. Voinescu, B.I. \& Szentagontai-Tatar, A. (2015). Sleep hygiene awareness: its relation to sleep Quality and Diurnal Preference, Journal of Molecular Psychiatry, 3(1):1-7.

16. Walch, O.J. \& Forger, D. B. (2017). A global quantification of "normal" sleep schedules using Smartphone data. Science Advances, 2(5), e1501705. 